\title{
Extremely cold and persistent stratospheric Arctic vortex in the winter of 2010-2011
}

\author{
HU YongYun ${ }^{1 *} \&$ XIA Yan \\ Laboratory for Climate and Ocean-Atmosphere Studies, Department of Atmospheric and Oceanic Sciences, School of Physics, Peking University, \\ Beijing 100871, China
}

Received June 12, 2012; accepted February 3, 2013; published online June 18, 2013

\begin{abstract}
Record ozone loss was observed in the stratospheric Arctic in the spring of 2011. In the present work, we show observational evidence that the record loss of Arctic ozone is due to the extremely cold and persistent stratospheric polar vortex in the winter of 2010-2011. The polar vortex was as usual in early winter, but was intensified twice in middle January and middle February, respectively, and remained anomalously strong and stable until early April, 2011. Record low polar temperatures and record high subpolar zonal winds occurred in February and March. Stratospheric wave activity was anomalously weak because waves were refracted equatorward by the anomalously strong polar night jet. With such an extremely cold and isolated environment, Arctic stratospheric ozone was largely depleted in March and early April, 2011. Corresponding to Arctic ozone depletion, the stratospheric Northern-Hemisphere Annular Mode (NAM) displayed anomalously strong high-polarity, and the positive stratospheric NAM propagated downward and led to anomalously strong positive NAM in the troposphere and near the surface.
\end{abstract}

ozone depletion, stratosphere, polar vortex, planetary wave, annular mode Citation: $\quad$ Hu Y Y, Xia Y. Extremely cold and persistent stratospheric Arctic vortex in the winter of 2010-2011. Chin Sci Bull, 2013, 58: 3155-3160, doi: 10.1007/
s11434- 013-5945-5

Observations showed that the stratospheric ozone layer has been stabilized and even demonstrated weak increasing since the late $1990 \mathrm{~s}$, consistent with the observed decline in ozone depleting substances (ODSs) that peaked in the middle 1990s [1-5]. In both stratospheric polar regions, ozone levels show similar tendencies to that of the global mean. Coupled chemistry-climate model (CCM) simulations, with projected stratospheric chlorine loading, predicted that globalmean stratospheric ozone will return to pre-1980 levels around 2050, and that Arctic and Antarctic ozone will return to pre-1980 levels by 2045 and 2075, respectively [1,2,4-6].

However, what happened in the past few years suggests that severe ozone depletion can still occur in both polar regions in the near future as long as ODS levels are not sufficiently low and meteorological conditions are appropriate. For example, the Antarctic ozone hole in 2006 is one of the most severe ones in both size and minimum ozone (see

*Corresponding author (email: yyhu@pku.edu.cn) http://ozonewatch.gsfc.nasa.gov/), and as what we will show below, record stratospheric ozone loss occurred in the stratospheric Arctic in spring 2011 [7]. The purpose of the present short paper is to investigate the evolution of the stratospheric Arctic vortex in the winter of 2010-2011 and how dynamical conditions of the Arctic polar vortex led to record ozone loss in the spring of 2011. In addition, we will also show that severe ozone depletion in the winter of 2010-2011 may have important influences on tropospheric and surface weather systems.

\section{Data and methods}

The data of temperatures and winds used here are from the National Center for Environmental Prediction/National Center for Atmospheric Research (NCEP/NCAR) reanalysis $[8,9]$. Total column ozone is from satellite observations of the Ozone Monitoring Instrument (OMI) and the Total 
Ozone Mapping Spectrometer (TOMS). The climatological means of temperatures, winds, and wave fluxes are averages over the period 1979-2008 (30 years). The climatological mean of TOMS total column ozone is averaged over 1997-2007, and the climatological mean of OMI is averaged over 2005-2011. Eliassen-Palm (EP) fluxes are calculated using the standard formula in the spherical coordinate $[10,11]$. NAM indices are calculated using the method in Baldwin and Dunkerton [12,13].

\section{Results}

Figure 1(a) shows time series of daily total-column polar ozone from OMI over the period from February 18 to May 31, 2011, together with climatological means from TOMS and OMI. Total polar ozone over February and March of 2011 is much lower than the climatological means, indicating severe Arctic ozone depletion in the spring of 2011. Polar ozone remained low until April 12 when it recovered to the climatological mean. The minimum total polar ozone occurred on March 9, with a value of about 275 Dobson Units (DU). Comparison with climatological means, which is about 400 DU on March 9, suggests that about 31\% polar ozone was depleted. Figure 1(b) is a snapshot of spatial distributions of total column ozone in Northern-Hemisphere middle and high latitudes on March 7, 2011. The lowest total ozone inside the vortex is close to $250 \mathrm{DU}$, while the highest total ozone outside the vortex is about $500 \mathrm{DU}$. The sharp contrast of total ozone indicates that the polar vortex is well isolated from its surroundings. With such an isolated environment, ozone-rich air in the subpolar region can hardly be transported into the vortex, and ozone inside the polar vortex was quickly depleted due to catalytic chemical reactions, resulting in extremely low ozone inside the vortex.

Figure 2 shows horizontal temperature distribution at 50
$\mathrm{hPa}$ and vertical cross-section of zonal-mean temperatures in the Northern Hemisphere on March 7, 2011. In Figure 2(a), temperatures over a large portion of the polar region are below $195 \mathrm{~K}$ (the region enclosed by the bold white contour), and the minimum polar temperature is lower than $192 \mathrm{~K}$. The polar temperature is below the threshold for the formation of Type-I polar stratospheric clouds (PSCs) (195 $\mathrm{K})$, suggesting that heterogeneous chemical reactions must be involved in causing such severe Arctic ozone depletion. Figure 2(b) shows that the layer with temperatures below $195 \mathrm{~K}$ is between about 30 and $70 \mathrm{hPa}$, and that the lowest temperature is located at about $50 \mathrm{hPa}$. These indicate that polar ozone depletion mainly occurred in the lower stratosphere.

To demonstrate time evolution of the Arctic vortex, we plot time series of daily area-weighted polar temperatures, the daily lowest polar temperature, and daily zonal-mean zonal winds at $65^{\circ} \mathrm{N}$ at $50 \mathrm{hPa}$ in Figure 3(a), (b), and (c), respectively. From November to early February, polar temperature was generally lower than the climatological mean. However, the departure from the climatological mean is still within one standard derivation. From middle February to early April, polar temperature became much lower than the climatological mean, and the departure from the climatological mean was beyond one standard derivation and even beyond two standard derivations sometimes. Record low values occurred in the period between March 7 and 17. Figure 3(b) shows that the lowest temperature inside the vortex dropped below $195 \mathrm{~K}$ since middle December and even dropped to $188 \mathrm{~K}$ in late January and middle February. Record low values of the lowest polar temperature occurred in March and early April. These all suggest that there was formation of PSCs, and that heterogeneous chemical reactions were responsible for severe ozone depletion in the stratospheric Arctic.

Figure 3(c) shows time series of zonal-mean zonal winds (a)

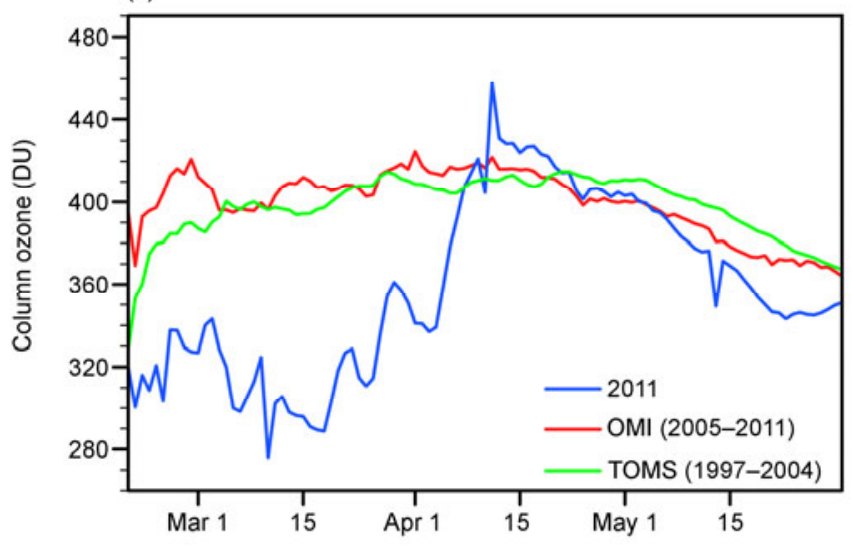

(b)

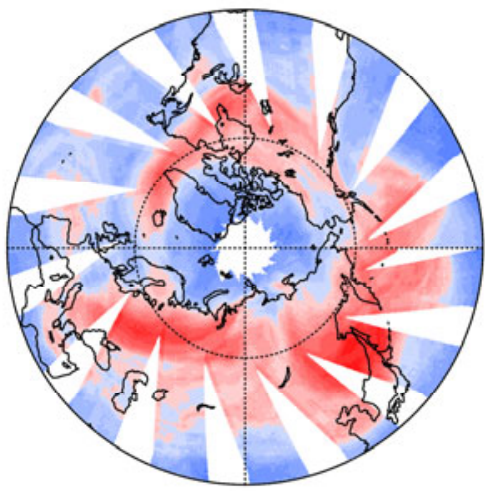

220256292328364400436472508

Figure 1 (a) Time series of area-weighted total column polar ozone between $70^{\circ}$ and $90^{\circ} \mathrm{N}$ for the spring of 2011 (blue), the climatological mean from TOMS (green), and the climatological mean from OMI (red), and (b) total column ozone in Northern-Hemisphere high-latitudes on March 7, 2011. 
(a)

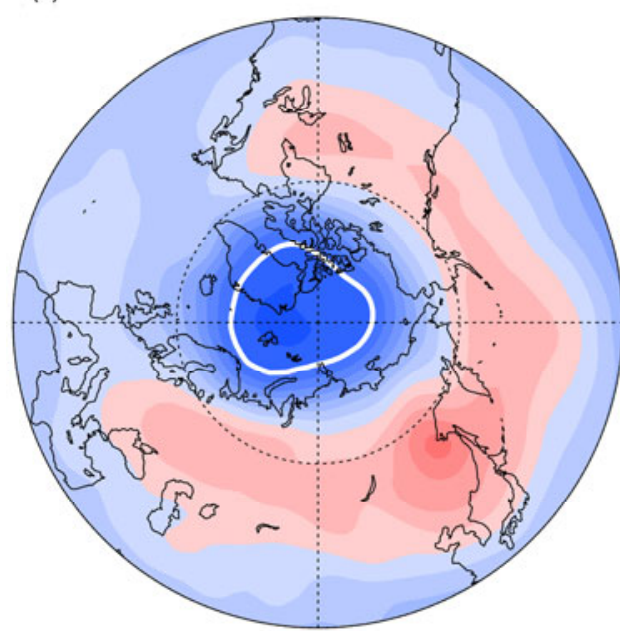

(b)

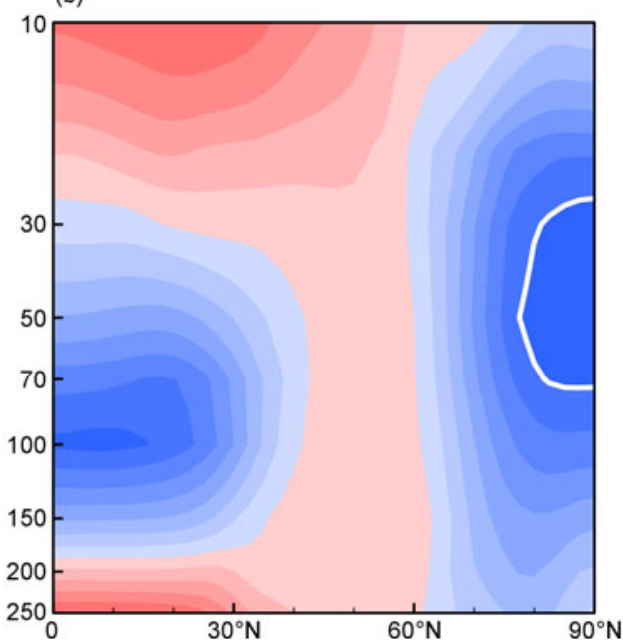

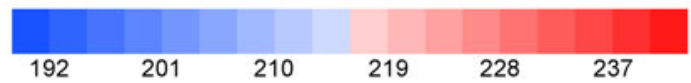

Figure 2 (a) $50 \mathrm{hPa}$ temperature, and (b) zonal mean temperature on March 7, 2011. White lines in (a) and (b) are the contour of $195 \mathrm{~K}$, which indicates the threshold temperature for Type-I PSC formation. Color interval is $3 \mathrm{~K}$.
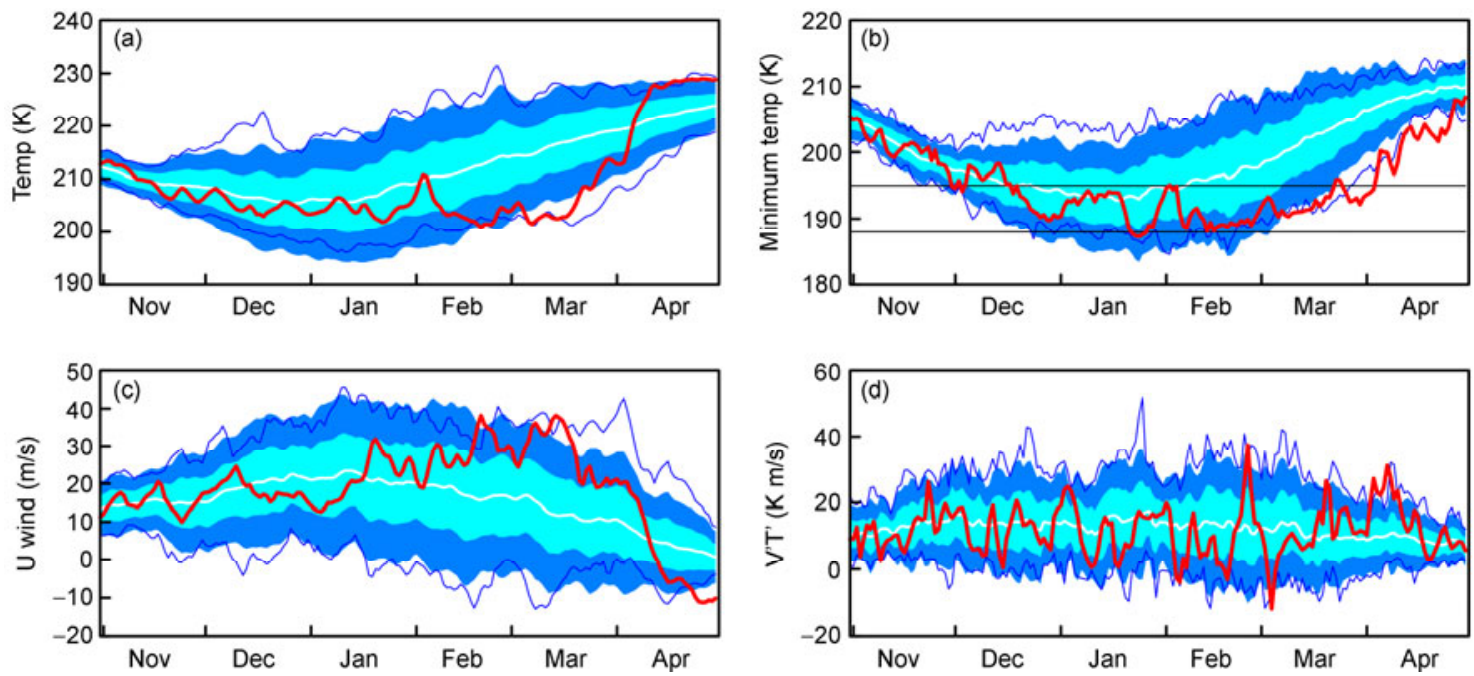

Figure 3 Time series of area-weighted Arctic temperatures $\left(65^{\circ}-90^{\circ} \mathrm{N}\right)$ (a), the minimum temperatures inside the Arctic (b), zonal-mean zonal winds at $65^{\circ} \mathrm{N}$ at $50 \mathrm{hPa}(\mathrm{c})$, and total eddy-heat fluxes area-weighted from $40^{\circ}$ to $90^{\circ} \mathrm{N}$ at $150 \mathrm{hPa}(\mathrm{d})$. In these plots, white lines are climatological means over $1979-$ 2010 , red lines indicate the values in the winter of 2010-2011, thin blue lines denote the daily maximum and minimum values over these years, shallow and dark blue shadings indicate one and two standard derivations, respectively. In (b), the two horizontal black lines mark the temperature thresholds for Type-I (195 K) and Type-II (188 K) PSC formation.

(the polar night jet stream) at $65^{\circ} \mathrm{N}$, which roughly marks the boundary of the vortex. Regardless fluctuations, subpolar zonal winds were slightly stronger than the climatological mean in November and early December in general, but weaker from early December to middle January. Zonal winds were accelerated in middle January, but still within the range of one standard derivation. After middle February, zonal winds were accelerated again and reached record high speeds on February 20 and March 13. Zonal winds became easterly on about April 10 when the vortex was broken down due to final warming.

During wintertime, subpolar zonal winds and stratospheric polar temperatures are all largely determined by planetary wave activity, in addition to radiative effect [10]. It is because planetary waves drive the poleward BrewerDobson circulation that has downward motion in polar regions. As polar air moves downward, air parcels are compressed by higher air pressure, resulting in adiabatic heating that warms polar air. Therefore, large variations of polar temperatures and the polar night jet are all due to strong 
fluctuations of wave activity. Figure 3(d) shows time series of area-weighted total eddy-heat fluxes at $150 \mathrm{hPa}$, which are usually used to represent wave fluxes from the troposphere to the stratosphere [11]. Eddy-heat fluxes were generally weaker than the climatological mean from November to middle March, although they were strong occasionally due to large fluctuations. The relatively weak wave activity is consistent with the anomalously cold and strong polar vortex over the same period, suggesting that the anomalously cold vortex is closely related the relatively weak wave activity in the winter of 2010-2011. Note that the anomalously strong wave disturbance in late February caused split of the vortex. There were also several other times in which the vortex was almost broken up or largely displaced off the polar cap. However, the vortex somehow quickly recovered.

To further illustrate the interaction between waves and the polar vortex, we plot EP flux vectors and zonal-mean zonal winds in February and March and their differences with climatological means in Figure 4, respectively. The climatological-mean EP flux vectors in both months are all upward and poleward in the north of $50^{\circ} \mathrm{N}$ and upward and equatorward at lower latitudes (Figure 4(a) and (d)), indicating wave propagation toward the polar stratosphere and subtropical upper troposphere, respectively. EP flux vectors in February and March of 2011 displayed large differences from their climatological means. Comparison between Figures 4(a) and (b) shows that the polar night jet in February of 2011 is much stronger than the climatological mean, and that stratospheric wave activity is much weaker than usual. The difference between Figure 4(b) and (a) is shown in Figure 4(c). The positive values of zonal winds indicate an anomalously strong polar night jet. Downward and equatorward arrows of EP flux vector differences indicate less wave fluxes into the polar stratosphere than the climatological mean. In other words, waves are refracted away from the polar stratosphere by the anomalously strong polar night jet. In March, zonal-wind differences also show positive values, and the maximum difference is up to $27 \mathrm{~m} \mathrm{~s}^{-2}$ (Figure $4(\mathrm{c})$ ), indicating a strongly intensified polar night jet.
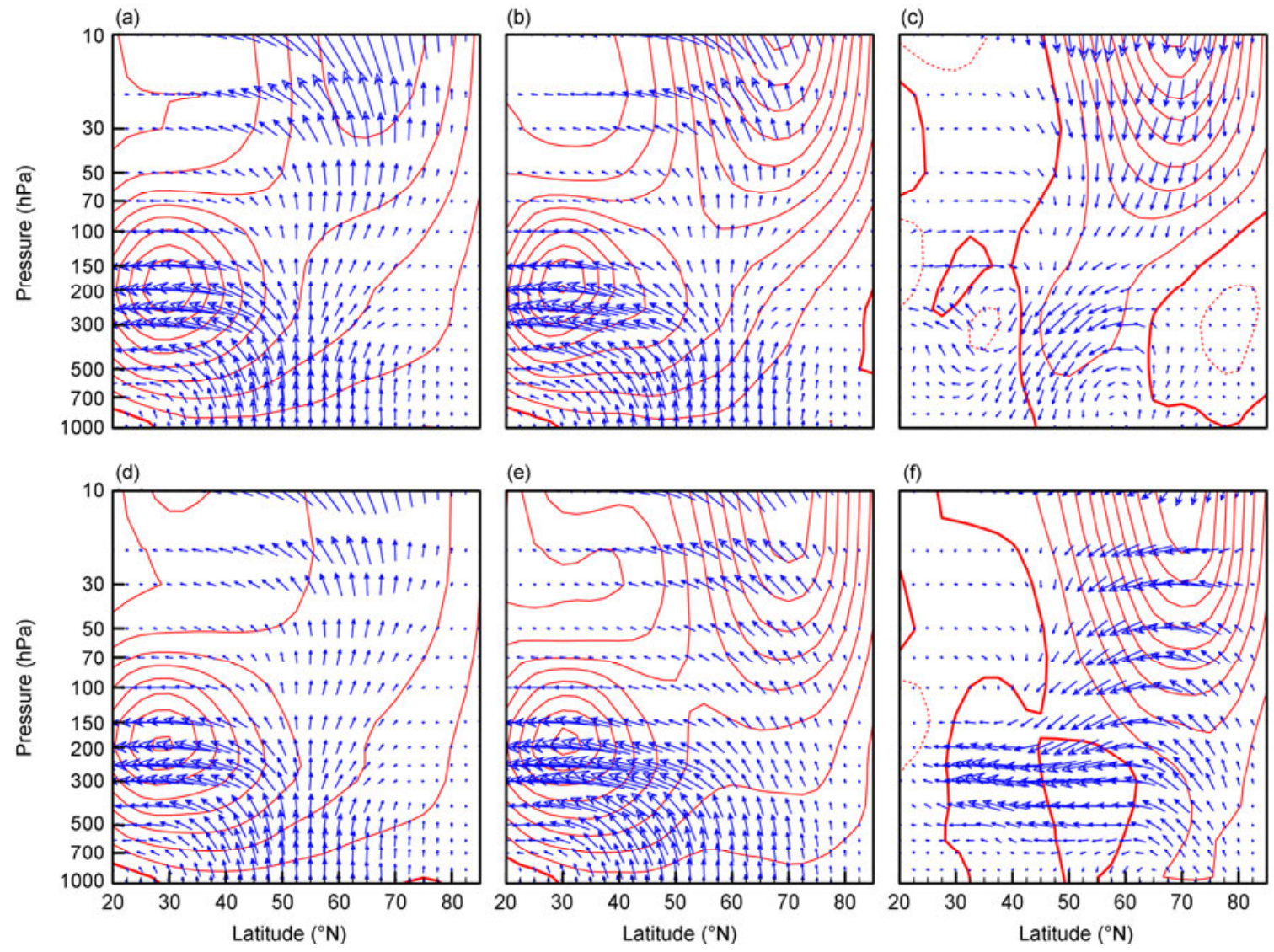

Figure 4 EP vectors in February and March, overlapped with zonal-mean zonal wind contours. Top: February, bottom: March. From left to right, the plots are for climatological mean EP flux vectors and zonal-mean zonal winds, EP flux vectors zna zonal-mean zonal winds in 2011, and differences between that in 2011 and the climatological mean, respectively. To show EP flux vectors at high levels, EP flux vectors are divided by the background air density. The scale length of arrows, $1 \mathrm{~cm}$, represents $1.0 \times 10^{8} \mathrm{~m}^{3} \mathrm{~s}^{-2}$. Because the vertical component of EP fluxes is about two orders smaller than the horizontal component, the vertical component is multiplied by 100 to display changes in EP flux vectors in the vertical direction. In (a), (b), (d), and (e), contour interval is $5 \mathrm{~m} \mathrm{~s}^{-1}$; in (c) and (f), contour interval is $3 \mathrm{~m} \mathrm{~s}^{-1}$. Solid lines denote positive values (westerly anomalies), and dotted-lines denote negative values (easterly anomalies). The bald solid line marks the $0 \mathrm{~m} \mathrm{~s}^{-1}$ wind anomaly. 
Poleward arrows of EP flux vector differences indicate that waves are refracted from the polar stratosphere toward the equator. The above results all suggest that the extremely cold and strong polar vortex in the winter of 2010-2011 is due to relatively weak wave activity.

Associated with the anomalously strong and stable polar vortex, the stratospheric Northern-Hemisphere annular mode (NAM) demonstrated persistent high-polarity in all winter time (Figure 5(a)). In early winter (before middle January), the stratospheric NAM demonstrated positive phase although the tropospheric NAM had negative phase. The stratospheric NAM remained in positive phase in the second half winter, and the stratospheric NAM has much greater values than that in the first half. In particular, the high-polarity of the stratospheric NAM was enhanced in middle February and peaked on about March 15, with the largest NAM index of about 14. This timing is consistent with the record high zonal-mean zonal winds in Figure 4(c), which was also intensified in middle February and middle March.

The stratospheric NAM showed downward propagation to the troposphere. From Figure 5(a), one can find that positive stratospheric NAM signals started propagating downward since January 13 and quickly reached the surface on January 17. In middle February, the enhanced stratospheric NAM showed downward propagation again and led to enhancement of the tropospheric NAM that reached maximum values in late March and April. The near surface NAM also had consistent changes in responding to downward propagation of the stratospheric NAM (Figure 5(b)). Before middle January, the surface NAM was in negative phase, same sign as that of the tropospheric NAM. The polarity changed to positive as the stratospheric NAM propagated downward and reached the surface. It is important to note that the surface NAM remained relatively weak until middle March when strong stratospheric NAM reached to the surface, indicating that the surface NAM is strongly influenced by downward propagation of the stratospheric NAM.

\section{Discussion and conclusions}

We have shown that the stratospheric Arctic polar vortex is extremely cold and persistent in the winter of 2010-2011. Record low temperatures are found inside the polar vortex, and record high-speed zonal winds are found in the subpolar region. The extremely low temperature led to formation of PSCs, and the extremely strong vortex provided with an isolated environment that prevents ozone-rich air transported into the polar vortex. Under such conditions, stratospheric Arctic ozone was largely destroyed by catalytic chemical reactions in middle February when sunlight returned to the Arctic, causing record low polar ozone. The case of the winter of 2010-2011 suggests that severe Arctic ozone depletion will likely occur in future as long as ODS levels are not sufficiently low and dynamic conditions are appropriate.

The extremely cold and persistent Arctic polar vortex was associated with relatively weak stratospheric wave activity in the winter of 2010-2011. The weak wave activity caused record low polar ozone in two aspects: (1) less ozone was transported into the Arctic polar vortex due to the
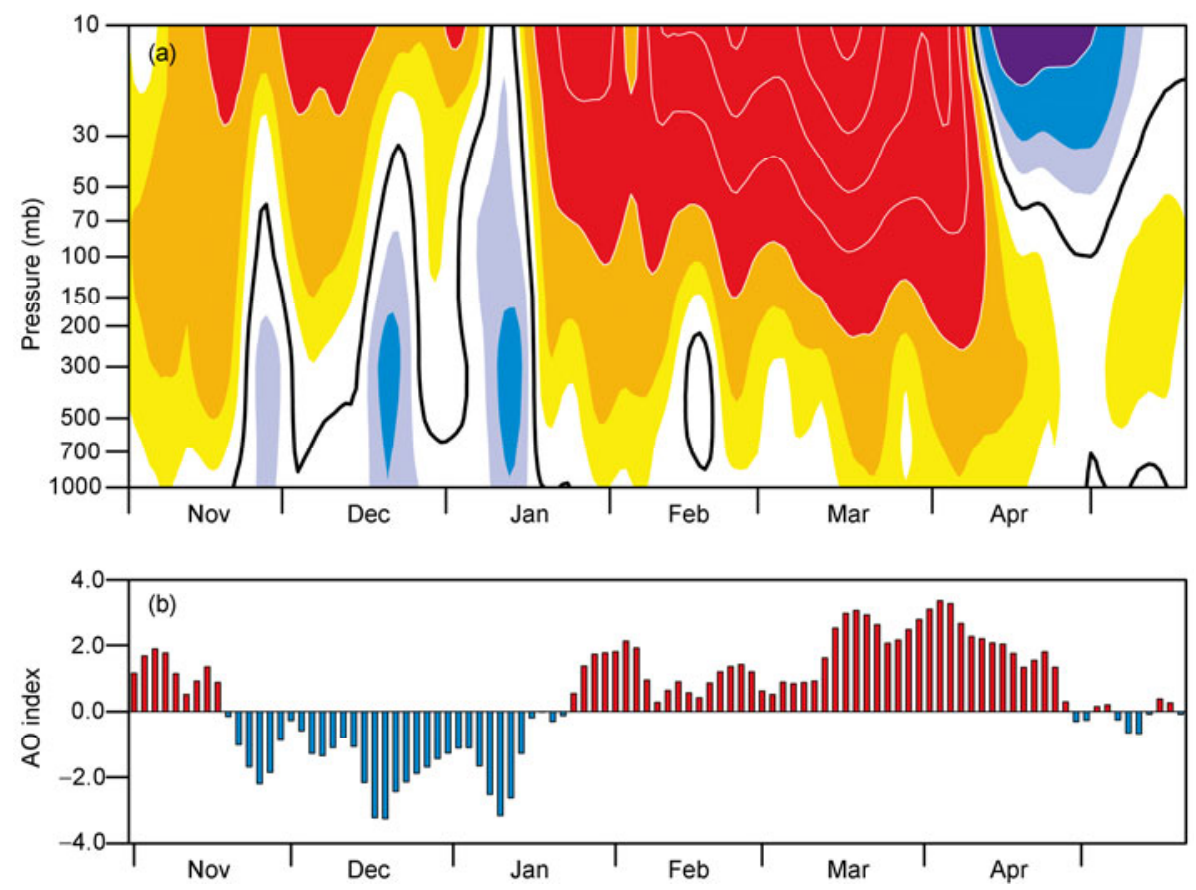

Figure 5 NAM index variations in the winter of 2010-2011. Top: height-time cross-section of NAM indices. Black lines denote contour zero, and white contour interval is 2. Bottom: time series of surface NAM indices, calculated from geopotential heights at $1000 \mathrm{hPa}$. 
weakened wave-driven Brewer-Dobson circulation, and (2) polar temperature remained low because of anomalously weakened wave-driven adiabatic heating, which benefits heterogeneous chemical reactions of ozone depletion. While it is difficult to diagnose whether the relatively weak wave activity in the stratosphere was due to natural variability, there is evidence that stratospheric preconditioning played an important role in causing reduction in stratospheric polar wave activity. For example, although tropospheric wave activity was stronger in March compared with the climatological mean (upward arrows in the troposphere in Figure 4(f)), stratospheric wave activity was weaker and propagated more equatorward (downward and equatorward arrows in the stratosphere in Figure 4(f)). These indicate that the relatively weak wave activity in the stratosphere was because the anomalously strong polar night jet refracted waves away from the polar stratosphere.

It is likely that the evolution process of the Arctic polar vortex in the winter of 2010-2011 involved positive feedbacks between ozone depletion and wave activity, as proposed by Randel and $\mathrm{Wu}$ [14] and $\mathrm{Hu}$ and Tung [15] We have mentioned above that the Arctic polar vortex was intensified twice. One is in middle January, and the other one is in middle February. The intensification of the polar vortex in middle January was more likely due to natural variability, while the second intensification might be a result of positive feedbacks between ozone depletion and wave activity. This is because catalytic chemical reactions started and caused ozone depletion in middle February when sunlight returns to the stratospheric Arctic. The radiative effect of ozone depletion caused anomalously low polar temperatures (Figure 3(a)) and thus enhanced temperature contrast between middle latitudes and the polar region. As a result, the polar night jet was accelerated. The strong polar night jet refracted waves away from the polar stratosphere (Figure 4(c) and (f)) and caused reduction of wave activity in the stratosphere. Reduced wave activity in turn caused further decrease in polar temperature and more ozone depletion. The feedback process would continue until the polar vortex broke down in early April.

Severe Arctic ozone depletion and possible positive feedbacks between ozone depletion and wave activity would also lead to enhanced strong positive stratospheric NAM in February and March. The positive stratospheric NAM was also intensified twice, same as that of the polar vortex. The coincidence of the second enhancement of the stratospheric NAM with that of Arctic ozone depletion suggests that the second enhancement was at least partly due to severe Arctic ozone depletion as well as positive feedback processes. Since NAM has important influences on surface climate [16], Arctic ozone depletion in the winter of 2010-2011 might have important influences on surface weather and climate at the high-latitude Northern Hemisphere.

This work was supported by the National Basic Research Program of China (2010CB428606) and the National Natural Science Foundation of China (40875042 and 41025018).

1 Weatherhead E C, Andersen S B. The search for signs of recovery of the ozone layer. Nature, 2006, 441: 39-45

2 Eyring V, Waugh D W, Bodeker G E, et al. Multimodel projections of stratospheric ozone in the 21st century. J Geophys Res, 2007, 112: D16303

$3 \mathrm{Hu}$ Y, Xia Y, Gao M, et al. Stratospheric temperature changes and ozone recovery in the 21st century. Acta Meteorol Sin, 2008, 23: 263-275

4 World Meteorological Organization. Scientific Assessment of Ozone Depletion: 2006, Global Ozone Research and Monitoring Project, Report No. 50, Geneva, Switzerland, 572, 2007

5 World Meteorological Organization. Scientific Assessment of Ozone Depletion: 2010, Global Ozone Research and Monitoring Project, Report No. 52, Geneva, Switzerland, 516, 2011

6 Chipperfield M. Nitrous oxide delays ozone recovery. Nat Geosci, 2009, 2: 742-743

7 Liu N, Huang F, Wang W. Monitoring of the 2011 spring low ozone events in the Arctic region. Chin Sci Bull, 2011, 56: 2893-2896

8 Kalnay E, Kanamitsu M, Kistler R, et al. The NCEP/NCAR 40-year reanalysis project. Bull Am Meteorol Soc, 1996, 77: 437-471

9 Kistler R, Kalnay E, Collins W, et al. The NCEP-NCAR 50-year reanalysis: Monthly means CD-ROM and documentation. Bull Am Meteorol Soc, 2001, 82: 247-267

10 Andrews D G, Holton J R, Leovy C B. Middle Atmosphere Dynamics. New York: Academic Press, 1987. 1-489

$11 \mathrm{Hu} \mathrm{Y}$, Tung K K. Interannual and decadal variations of planetary wave activity, stratospheric cooling, and Northern Hemisphere annular mode. J Clim, 2002, 15: 1659-1673

12 Baldwin M P, Dunkerton T J. Propagation of the Arctic Oscillation from the stratosphere to the troposphere. J Geophys Res, 1999, 104: 30937-30946

13 Baldwin M P, Dunkerton T J. Stratospheric harbingers of anomalous weather regimes. Science, 200, 1294: 581-584

14 Randel W J, Wu F. Cooling of the Arctic and Antarctic polar stratosphere due to ozone depletion. J Clim, 1999, 12: 1467-1479

15 Hu Y, Tung K K. Possible ozone-induced long-term changes in planetary wave activity in late winter. J Clim, 2003, 16: 3027-3038

16 Gong D, Wang S, Zhu J. Arctic oscillation influence on daily temperature variance in winter over China. Chin Sci Bull, 2004, 49: 637-642

Open Access This article is distributed under the terms of the Creative Commons Attribution License which permits any use, distribution, and reproduction in any medium, provided the original author(s) and source are credited. 